\title{
Differential Distribution and Function of Hyperpolarization- Activated Channels in Sensory Neurons and Mechanosensitive Fibers
}

\author{
Thanh N. Doan, ${ }^{1}$ Kevin Stephans, ${ }^{1}$ Angelina N. Ramirez, ${ }^{1}$ Patricia A. Glazebrook, ${ }^{1}$ Michael C. Andresen, ${ }^{2}$ and \\ Diana L. Kunze ${ }^{1}$ \\ ${ }^{1}$ Rammelkamp Center for Education and Research, MetroHealth Medical Center, and Department of Neurosciences, Case Western Reserve University, \\ Cleveland, Ohio 44109-1998, and 2Department of Physiology, Oregon Health Sciences University, Portland, Oregon 97239
}

\begin{abstract}
Sensory neurons express hyperpolarization-activated currents $\left(I_{\mathrm{H}}\right)$ that differ in magnitude and kinetics within the populations. We investigated the structural basis for these differences and explored the functional role of the $I_{\mathrm{H}}$ channels in sensory neurons isolated from rat nodose ganglia. Immunohistochemical studies demonstrated a differential distribution of hyperpolarization-activated cyclic nucleotide-gated $(\mathrm{HCN})$ protein $(\mathrm{HCN} 1, \mathrm{HCN} 2, \mathrm{HCN} 4)$ in sensory neurons and peripheral terminals. $\mathrm{HCN} 2$ and $\mathrm{HCN} 4 \mathrm{immunoreactivity}$ was present in all nodose neurons. In contrast, only $20 \%$ of the total population expressed HCN1 immunoreactivity. HCN1 did not colocalize with IB4 (a marker for C-type neurons), and only 15\% of HCN1-positive neurons colocalized with immunoreactivity for the vanilloid receptor VR1, another protein associated primarily with C-type neurons. Therefore, most HCN1-containing neurons were A-type neurons. In further support, $\mathrm{HCN} 1$ was present in the mechanosensitive terminals of myelinated but not unmyelinated sensory fibers, whereas HCN2 and HCN4 were present in receptor terminals of both myelinated and unmyelinated fibers. In voltage-clamp studies, cell permeant cAMP analogs shifted the activation curve for $I_{\mathrm{H}}$ to depolarized potentials in C-type neurons but not A-type neurons. In current-clamp recording, $\mathrm{CsCl}$, which inhibits only $I_{\mathrm{H}}$ in nodose neurons, hyperpolarized the resting membrane potential from $-63 \pm 1$ to $-73 \pm 2 \mathrm{mV}$ and nearly doubled the input resistance from 1.3 to $2.2 \mathrm{G} \Omega$. In addition, action potentials were initiated at lower depolarizing current injections in the presence of $\mathrm{CsCl}$. At the sensory receptor terminal, $\mathrm{CsCl}$ decreased the threshold pressure for initiation of mechanoreceptor discharge. Therefore, elimination of the $I_{\mathrm{H}}$ increases excitability of both the soma and the peripheral sensory terminals.
\end{abstract}

Key words: $I_{\mathrm{H}}$; HCN1; HCN2; HCN4; sensory; nodose; baroreceptors

\section{Introduction}

The hyperpolarization-activated cation current $\left(I_{\mathrm{H}}\right)$ is usually associated with cardiac pacemaker activity or, in neurons, oscillatory behavior (DiFrancesco, 1985; Denyer and Brown, 1990; Pape, 1996; Kaupp and Seifert, 2001). $I_{\mathrm{H}}$ is expressed in the soma of the viscerosensory and somatosensory neurons that generally exhibit neither pacemaker activity nor oscillatory potentials (Mayer and Westbrook, 1983; Doan and Kunze, 1999). The soma is quiescent except in response to a depolarizing stimulus, usually the arrival of action potentials generated at the peripheral sensory receptors. Therefore, $I_{\mathrm{H}}$ serves a different purpose in these nonoscillatory neurons.

The channels underlying $I_{\mathrm{H}}$ belong to the hyperpolarizationactivated cyclic nucleotide-gated (HCN) family of ion channels (HCN1-4), members of which differ with regard to their cAMP sensitivity and the time and voltage dependence of activation (Ludwig et al., 1998, 1999; Santoro et al. 1998, 2000; Ishii et al.,

Received Nov. 21, 2003; revised Feb. 11, 2004; accepted Feb. 16, 2004.

This work was supported by National Institutes of Health Grant HL061436 to D.L.K.

Correspondence should be addressed to Dr. Diana L. Kunze, Rammelkamp Center, R326, MetroHealth Systems, 2500 MetroHealth Drive, Cleveland, OH 44109-1998. E-mail: dkunze@metrohealth.org. DOI:10.1523/JNEUROSCI.5156-03.2004

Copyright $\odot 2004$ Society for Neuroscience $\quad$ 0270-6474/04/243335-09\$15.00/0
1999, 2001; Seifert et al., 1999; Vaccari et al., 1999; Moroni et al., 2000). The distribution of the specific isoforms would be expected to have important implications for neuronal type and function.

In this study, we used reverse transcriptase (RT)-PCR, immunohistochemistry, and electrophysiology to relate expression to function of specific HCN channels in the soma of visceral sensory neurons of the nodose ganglion. To extend the studies beyond the soma, we also examined the expression of the $\mathrm{HCN}$ protein in the sensory terminals of a particular subpopulation of nodose neurons, the mechanoreceptors of the aortic arch (arterial baroreceptors). These receptors lie in the adventitial layer of the vessel wall and respond to distortion of the terminal ending produced by changes in arterial pressure. Approximately $15-20 \%$ of arterial baroreceptors are A-type neurons with myelinated axons, whereas the other $80-85 \%$ of the population have unmyelinated axons (C-type neurons).

We asked whether HCN family members are differentially distributed within the sensory neuron population and addressed functional implications of the distribution. We demonstrated that $\mathrm{HCN} 1$ expression is primarily confined to A-type neurons, whereas HCN2 and HCN4 are expressed in both A-type and $\mathrm{C}$-type neurons in the ganglion. The absence of HCN1 in C-type 
neurons supports previous studies (Doan and Kunze, 1999), showing that $I_{\mathrm{H}}$ in C-type neurons gives rise to inward current with slow activation that is consistent with the expression of HCN2 and HCN4 as described in the present study. This is in contrast to the more rapid activation time of A-type neurons that is representative of HCN1. Notably, we also provide evidence that inhibition of $I_{\mathrm{H}}$ increases the input resistance at the resting membrane potential and, thus, decreases the current threshold for spike initiation at both the soma and peripheral terminals rendering the cells more excitable.

\section{Materials and Methods}

All of the protocols used in harvesting tissue have been approved by the Case Western Reserve University Animal Research Committee.

RT-PCR amplification of nodose ganglia HCN channel subunit cDNA fragments. Nodose ganglia from adult rats were excised under halothane anesthesia and stored in RNAlatter (Ambion, Austin, TX) at $-20^{\circ} \mathrm{C}$. mRNA from nodose ganglia and brain were isolated using the MicroPoly(A)Pure Kit (Ambion). Poly-(A+) mRNA was quantitated by spectrophotometric absorbance at $260 \mathrm{~nm}$ and stored at $-80^{\circ} \mathrm{C}$.

Primer design. Sets of specific primers were designed to amplify unique DNA fragments corresponding to regions of rat HCN1, HCN2, HCN3, and HCN4 by RT-PCR. Primer sequence and locations in published cDNA sequences in GenBank (National Center for Biotechnology Information) were as follows: HCN1 (GenBank accession number AF247450), 5'-CAA TCT CCA CCA GTC TAC ACA GCG ACC AG-3' [sense primer; 2028-2056 nucleotide (nt)] and 5' - TGT CTG AAC AAG GTG ACA CGC TGT GGC AC-3' (antisense primer; 2668-2640 nt); HCN2 (GenBank accession number AF247451.1), 5'-AGC TCG GGT GTG TTC AAC AAC CAG G-3' (sense primer; 1867-1891 nt) and 5' TCA CAA GTT GGA AGA GAG GCG CGA G-3' (antisense primer; 2505-2481 nt); HCN3 (GenBank accession number AF247452), 5' -GAC ACT CGC CTC ACT GAC GGA TCC TAC-3' (sense primer; 1441-1467 nt) and 5' -TGC TGA GCG TCT AGC AGA TCG AGC CAG-3' (antisense primer; 1950-1924 nt); HCN4 (GenBank accession number AF247453), 5' -TGG CAG CTG GTC CAC CAA GTA CAC CAG AG-3' (sense primer; 3181-3209 nt) and 5'-TAG ACG GCA GTT TGG AGC GTA CTG GCT CG-3' 3' (antisense primer; 3816-3789 nt).

$R T$-PCR. Poly-A mRNA (100 ng) was heat-denatured at $70^{\circ} \mathrm{C}$ for 5 min and then reverse-transcribed into first-strand cDNA using a mixture of random hexameric, unlabelled deoxynucleotides and MuLV reverse transcriptase (First-Strand cDNA Synthesis Kit; PerkinElmer Life Sciences, Emeryville, CA) at $42^{\circ} \mathrm{C}$ for $1 \mathrm{hr}$. The first-strand cDNA products were used directly as templates for PCR amplification. PCR was performed with the Advantage PCR system (Clontech, Cambridge, UK), and the amplification temperature protocol was as follows: one cycle (2 min at $\left.95^{\circ} \mathrm{C}\right), 35$ cycles $\left(15 \mathrm{sec}\right.$ at $94^{\circ} \mathrm{C} ; 15 \mathrm{sec}$ at $55^{\circ} \mathrm{C} ; 1 \mathrm{~min}$ at $\left.68^{\circ} \mathrm{C}\right)$, one cycle $\left(10 \mathrm{~min}\right.$ at $\left.72^{\circ} \mathrm{C}\right)$. PCR products of $\mathrm{HCN} 1, \mathrm{HCN} 2, \mathrm{HCN} 3$, and HCN4 from the nodose ganglia and brain were resolved by electrophoresis on $1.2 \%$ agarose gels and transferred to BrightStar-Plus nylon membranes (Ambion) as recommended by the manufacturer. After transfer, the membranes were baked at $80^{\circ} \mathrm{C}$ in a vacuum oven. Channel-specific PCR products were identified by hybridization to radiolabeled internal oligonucleotides specific for HCN1, HCN2, HCN3, and HCN4. The internal oligonucleotides were as follows: HCN1 $\left(5^{\prime}\right.$-TCA GCC ATC CTT TCA CCC TGC TCC TAC AC-3'; 2112-2140 nt), HCN2 (5'-GAG ATT GTC AAA TAT GAC CGT GAG ATG GTG C-3'; 1909-1939 nt), HCN3 (5'-AAC CAC TGG TAC ACG CAC CTC TGC AG-3; 1811-1836 nt), and HCN4 (5'-ACT CCT CAG GGG AGT CGA TGG CTG CCT TC-3'; 3541-3569 nt). Radiolabeling was accomplished with T4 polynucleotide kinase in the presence of $\left[\gamma^{32} \mathrm{P}\right] \mathrm{ATP}$. After the blots were prehybridized in ultrasensitive hybridization solution (Ambion) at $44^{\circ} \mathrm{C}$ for $1 \mathrm{hr},\left[{ }^{32} \mathrm{P}\right]$ labeled probe (at $10^{6} \mathrm{cpm} / \mathrm{ml}$ ) was added and hybridized at $44^{\circ} \mathrm{C}$ for up to $16 \mathrm{hr}$. After hybridization, the blots were washed first with $2 \times \mathrm{SSC} /$ $0.1 \%$ SDS at room temperature followed by a more stringent wash with $0.1 \times \mathrm{SSC} / 0.1 \%$ SDS at $44^{\circ} \mathrm{C}$. Blots were exposed to BioMaxMS film (Kodak, Rochester, NY) at $-80^{\circ} \mathrm{C}$ with an intensifying screen.

Immunohistochemistry. We used the following antibodies in this study:
HCN1, HCN2, and HCN4 rabbit polyclonal antibodies (Alomone Labs, Jerusalem, Israel); neurofilament (NF) mouse monoclonal antibodies: 200-clone NE14, 160-clone NN18, 68-clone NR4 (Sigma, St. Louis, MO); peripherin mouse monoclonal antibody (Ab) (Chemicon, Temecula, CA); VR1 (vanilloid receptor) rabbit polyclonal antibody (Oncogene Sciences, Uniondale, NY), and VR1 guinea pig polyclonal (Chemicon). FITC-labeled IB4 was purchased from Sigma. Antibodies were diluted as follows: VR1 rabbit 1:200, VR1 guinea pig 1:500, HCN 1:100, NF mixture $1: 100$, peripherin 1:200, and protein gene product (PGP) $9.51: 50$. For a negative control, blocking solution followed by the appropriate secondary $\mathrm{Ab}$ was used. The immunizing peptides were used to preabsorb the antibodies for a second negative control. After overnight incubation, the antibodies were visualized with either mouse or rabbit IgG tagged with FITC or RITC.

Nodose ganglia were excised from neonatal [ postnatal day (P) 0-P3] or older (P21-P60) Sprague Dawley rats. Tissue was collected from neonatal rats after asphyxiation by $\mathrm{CO}_{2}$ inhalation and from older animals under halothane anesthesia followed by decapitation. The ganglia were processed in one of two ways as described previously (Glazebrook et al., 2002).

Aortic arches from halothane-anesthetized adult Sprague Dawley rats were isolated and fixed in 3\% paraformaldehyde. The adventitia containing the baroreceptors was separated from the arterial wall and placed in paraformaldehyde overnight (Kunze et al., 1984). The tissue was blocked for nonspecific staining in PBS containing 10\% normal donkey serum, 0.3\% Triton X-100 (Pierce, Rockford, IL), and 1\% BSA (Jackson ImmunoResearch, West Grove, PA) followed by incubation in a primary $\mathrm{Ab}$ mixture consisting of an HCN channel Ab and an Ab to aid in the localization of the nerve terminals (PGP 9.5, the neurofilament mixture, or peripherin). Secondary antibodies from appropriate host animals (Jackson Laboratories, Bar Harbor, ME) were sequentially applied or mixed in a mixture in PBS containing $0.3 \%$ Triton X-100 and 10\% donkey serum. The secondary antibodies were tagged with FITC, Rhodamine Red-X, or cyanin 5 . The adventitia was mounted with Vectashield or $50 \%$ glycerol in PBS with 2\% N-propyl gallate on glass slides, coverslipped, and viewed using a Leica (Nussloch, Germany) TCS SP spectral confocal microscope.

Electrophysiology using whole-cell patch configuration. Nodose ganglia were excised from neonatal (1-3 d of age) Sprague Dawley rats, and the neurons were isolated and cultured as described previously (Doan and Kunze, 1999). Nodose ganglia were also excised from older (P21-P60) Sprague Dawley rats that underwent halothane anesthesia followed by decapitation (Doan and Kunze, 1999). Electrophysiological experiments were performed on isolated neurons $4-24 \mathrm{hr}$ after plating onto glass coverslips as described previously (Doan and Kunze, 1999). During voltage-clamp experiments, the series resistance was between 3 and 8 $\mathrm{M} \Omega$, and the capacitance and series resistance were $\sim 40-80 \%$ compensated. The voltage error was approximately $\pm 3 \mathrm{mV}$. A gravity-fed perfusion system was used to exchange extracellular solutions at a rate of $\sim 1$ $\mathrm{ml} / \mathrm{min}$. Whole-cell recordings were done at room temperature. For voltage- and current-clamp studies, the following solutions were used (in $\mathrm{mm}$ ): bath or physiological saline, $137 \mathrm{NaCl}, 5.4 \mathrm{KCl}, 1 \mathrm{MgCl}_{2}, 2 \mathrm{CaCl}_{2}$, 10 glucose, and 10 HEPES, $\mathrm{pH} 7.4$, with $\mathrm{NaOH}$; pipette, $145 \mathrm{~K}$-aspartate, $5 \mathrm{NaCl}, 1.95 \mathrm{CaCl}_{2}, 2.2 \mathrm{EGTA}, 2 \mathrm{MgCl}_{2}, 10$ glucose, and 5 HEPES, pH 7.3, with $\mathrm{KOH}$. Perforated patch recording was used in approximately onehalf of cAMP studies. The patch electrode for those studies contained (in $\mathrm{mm}$ ): $10 \mathrm{NaCl}, 5 \mathrm{MgCl}_{2}, 50 \mathrm{KCl}, 50 \mathrm{~K}_{2} \mathrm{SO}_{4}$, and $10 \mathrm{HEPES}, \mathrm{pH} 7.1$, with $\mathrm{KOH}$. The pipette solution included nystatin $(25-50 \mu \mathrm{g} / \mathrm{ml})$. The results were not different from those with open-patch recording. ZD7288 was purchased from Tocris Cookson (Ellisville, MO). All other chemicals were purchased from Sigma.

In vitro aortic arch-aortic nerve preparation. Male Sprague Dawley rats (200-250 gm) were anesthetized with sodium pentobarbital (40-50 mg/ $\mathrm{kg}$, i.p.). The rats were mechanically ventilated via tracheostomy. After midline thoracotomy, the aortic arch and left aortic nerve were carefully isolated in situ under dissecting microscope according to methods described previously in detail (Andresen and Yang, 1990). The arch and nerve were then removed and mounted in a temperature-regulated (36$37^{\circ} \mathrm{C}$ ) perfusion dish, pinned to approximate the in situ configuration, and covered with warmed mineral oil. The arch was continuously per- 


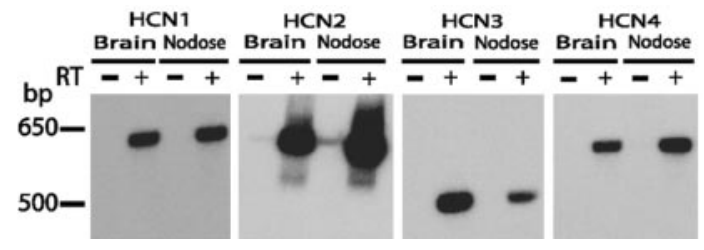

Figure 1. $H C N 1, H C N 2, H C N 3$, and $H C N 4 m R N A$ is expressed in nodose ganglia. PCR products resulting from the amplification of first-strand CDNA prepared with (+) or without (-) RT from nodose ganglia or brain poly A + RNA with HCN1-, HCN2-, HCN3-, and HCN4-specific oligonucleotides were separated by electrophoresis and transferred to nylon membranes (Ambion). After Southern hybridization with ${ }^{32} \mathrm{P}$-labeled specific internal oligomers, the autoradiogram showed a positive signal for all four channels from nodose and rat brain in the $(+) R T$ lanes and no signals in the control (-) RT. The oligonucleotide probes amplify CDNA of 641 bp for HCN1, 638 bp for HCN2, 509 bp for HCN3, and 635 bp for HCN4.

fused $\left(3 \mathrm{ml} / \mathrm{min}\right.$ ) with PBS continuously gassed with $95 \% \mathrm{O}_{2} / 5 \% \mathrm{CO}_{2}$. PBS contained the following (in mM): $120 \mathrm{NaCl}, 4.8 \mathrm{KCl}, 1.2 \mathrm{KH}_{2} \mathrm{PO}_{4}, 1.2$ $\mathrm{MgSO}_{4}, 25 \mathrm{NaHCO}_{3}, 5.5$ dextrose, and $1.1 \mathrm{CaCl}_{2}$. A Statham P23 db transducer was used to measure perfusion pressure.

Baroreceptor discharge. Each preparation was perfused at a constant, pulseless, conditioning perfusion pressure of $80 \mathrm{mmHg}$. The aortic nerve was divided to fine strands containing a single active baroreceptor and recorded differentially with a pair of Pt-IR electrodes and a high-gain preamplifier (PAR113; Princeton Instruments, Trenton, NJ). One baroreceptor unit per preparation was studied. After isolation of a regularly discharging baroreceptor, slow ramps of increasing pressure $(<2$ $\mathrm{mmHg} / \mathrm{sec}$ ) were used to test discharge properties. Only regularly discharging baroreceptors were studied, because their discharge patterns allowed precise measurements of threshold and sensitivity. This pattern is found primarily in A-type baroreceptors with myelinated axons. Typically, ramps began at $20 \mathrm{mmHg}$, ranged up to $150-170 \mathrm{mmHg}$, and were repeated at 5, 10, and $15 \mathrm{~min}$. After a period of $15 \mathrm{~min}$ perfusion with PBS solution, perfusate was switched to one containing fixed concentrations of added $\mathrm{CsCl}(0.5,1$, and $5 \mathrm{~mm})$, and ramps were repeated at $5 \mathrm{~min}$ intervals for $15 \mathrm{~min}$ at each concentration. Pressure and discharge were recorded on frequency modulation magnetic tape for analysis. Pressure was digitally sampled by a custom personal computer-based program at 100 samples/sec. Pressure threshold was calculated as the average of the 10 pressure values measured at the corresponding times of occurrence of each of the first 10 action potentials. This avoided basing threshold on the location of a single spike. Discharge rate was calculated as the instantaneous frequency (reciprocal of the interspike interval). Threshold frequency was averaged from the first 10 spikes after reaching threshold. The maximum discharge frequency was the mean of a 40-point interval at the highest pressures where discharge no longer increased with additional increases in pressures. Sensitivity was measured by linear regression fits to an initial section of the pressure-discharge relationship above threshold. The baroreceptor discharge properties (threshold pressure, threshold frequency, maximum discharge frequency, and sensitivity) were normalized as a percentage of the 15 min control value (zero cesium) values. Normalized values were compared initially by ANOVA for concentration effects and then by post hoc difference testing with Scheffe tests (GB-Stat 6.0; Dynamic Microsystems, Silver Spring, MD). $p$ values $<0.05$ were considered significant. All data are expressed as mean \pm SE.

\section{Results}

\section{Identification of $I_{\mathrm{H}}$ : RT-PCR and immunohistochemistry of} nodose neurons

mRNA for HCN1-4 was detected in nodose ganglia as demonstrated by RT-PCR (Fig. 1). To localize the expression of the proteins in neurons, antibodies against $\mathrm{HCN} 1, \mathrm{HCN} 2$, and HCN4 were used in ganglion slices and in primary cultures (Fig. 2). An Ab against $\mathrm{HCN} 3$ was not commercially available. HCN2 and HCN4 were expressed in all neurons of the nodose ganglion at differing levels of intensity (Fig. $2 B, C$ ). In contrast, HCN1 immunoreactivity was confined to a subpopulation of nodose
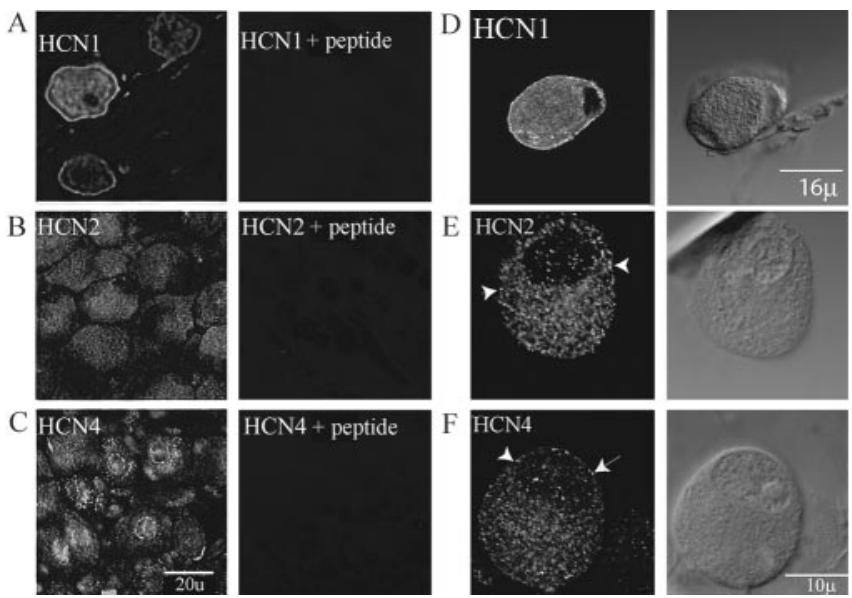

Figure 2. $\mathrm{HCN1}, \mathrm{HCN} 2$, and $\mathrm{HCN} 4$ immunoreactivity in nodose neurons. A-C, HCN immunoreactivity identified in $6-10 \mu \mathrm{m}$ sections of nodose ganglion. HCN1 immunoreactivity was localized to a small subpopulation of neurons and, in most of these cells, was heavily localized at the plasma membrane $(A)$. HCN2 $(B)$ and HCN4 $(C)$ immunoreactivity was present in all neurons in the ganglion. $D-F$, Single confocal sections through cultured nodose neurons selected for expression of $\mathrm{HCN} 1(D), \mathrm{HCN} 2(E)$, and HCN4 $(F)$. Heavy labeling at the membrane is again shown for HCN1 (D). Patches of HCN2 and HCN4 immunoreactivity were located at the cell perimeter; examples are indicated by the arrows $(E, F)$. The light microscopic differential interference contrast image is also shown for each neuron. The calibration bar in Calso applies to $A$ and $B$, whereas calibration in $F$ applies to $E$. The antibodies were preabsorbed with the immunizing peptide as shown in the figure. A control for nonspecific staining omitted the primary $A b$ (data not shown).

neurons, 21 and 19\% of the neurons in two ganglia. Many of these cells were intensely stained at the cell periphery with lighter intracellular staining (Fig. 2A). Because the individual neurons are surrounded by satellite cells that may also express $\mathrm{HCN}$ protein, we examined the distribution in isolated dissociated neurons from which the satellite cells had been removed (Glazebrook et al., 2002). A single confocal section of an isolated cultured nodose neuron shows HCN1 immunoreactivity in a continuous ring at the membrane (Fig. 2D). This contrasts with HCN2 and HCN4 immunoreactivity that is more sparsely distributed at the surface membrane as shown in confocal sections (Fig. 2E,F). Because $\mathrm{HCN} 1$ was restricted to a subpopulation that included many of the larger diameter neurons, we asked whether it was expressed specifically in A-type neurons (with myelinated fibers) or C-type neurons (with unmyelinated fibers). We examined ganglion slices for colocalization of $\mathrm{HCN} 1$ with the plant isolectin IB4, a marker for a subpopulation of neurons with unmyelinated fibers (Kitchener et al., 1993; Wang et al., 1994). HCN1 did not colocalize with IB4 (Fig. 3A). Immunoreactivity for another indicator of C-type neurons, the VR1 receptor, also did not colocalize with the majority of labeled $\mathrm{HCN} 1$ neurons, in particular those that showed intense HCN1 immunoreactivity (Fig. 3B). However, weak immunoreactivity for $\mathrm{HCN} 1$ was present in 15\% (342 of 2168) of VR1-containing neurons.

\section{CsCl specifically inhibits $I_{\mathrm{H}}$}

All nodose neurons functionally express the hyperpolarizationactivated cation inward current $I_{\mathrm{H}}$, although it is significantly larger in A-type neurons versus $\mathrm{C}$-type neurons, as defined by the presence of TTX-resistant sodium current in the latter (Doan and Kunze, 1999). The current is effectively blocked by superfusing the neuron with 1-5 mM CsCl added to the extracellular bathing solution and is fully and rapidly recoverable during washout of CsCl (Fig. 4A-C). A pharmacological inhibitor for $I_{\mathrm{H}}$, ZD7288 


\section{A}
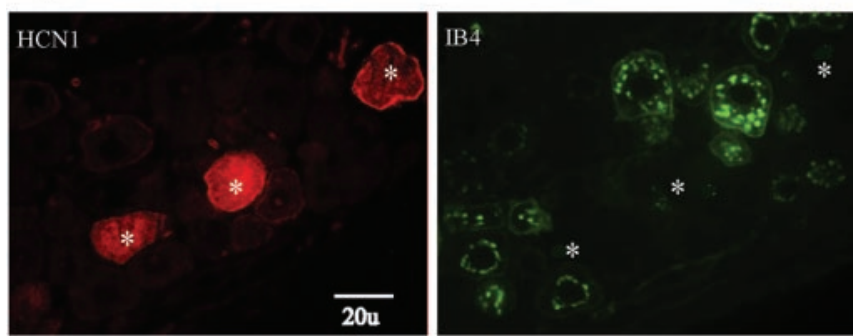

B
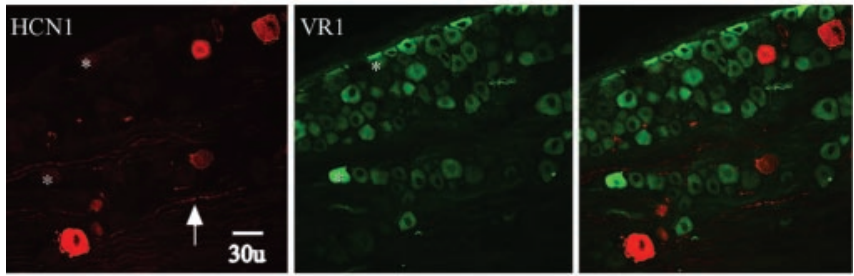

Figure 3. Colocalization of HCN1 and IB4 or VR1. A, Nodose ganglion section immunolabeled with rabbit HCN1 Ab (left) and IB4 lectin (right). HCN1 neurons do not contain IB4. Three of the HCN1-labeled neurons are identified by an asterisk. $B$, Nodose section labeled with anti-HCN1 $\mathrm{Ab}$ (left) and anti-VR1 Ab (center) is shown overlaid on the right. The neurons with strong labeling for HCN1 did not coexpress VR1, but weaker HCN1 staining is seen on two VR1 (*)immunoreactive neurons. The arrow indicates an example of HCN1 axonal labeling.

(Harris and Constanti, 1995), at $100 \mu \mathrm{M}$ inhibited $70-90 \%$ of $I_{\mathrm{H}}$ $($ at $-120 \mathrm{mV})$ within $2.6-6.5 \mathrm{~min}(n=7)$ (Fig. $4 D-F)$. Full block was generally complete within $10 \mathrm{~min}$. Block by this compound has been shown to be voltage dependent (Shin et al., 2001). Because the block by ZD7288 is slow and poorly reversible, in contrast to block by $\mathrm{CsCl}$, additional investigation in nodose neurons was pursued with $\mathrm{CsCl}$.

The monovalent cation $\mathrm{Cs}^{+}$has been reported to inhibit other potassium currents such as the inward rectifier potassium currents (IRKs) (Kubo et al., 1993; Wischmeyer et al., 1995), human ether-a-go-go-related gene (Arcangeli et al., 1995), and the delayed rectifier potassium currents (Block and Jones, 1996). Nodose neurons in rat do not appear to functionally express IRK (Doan and Kunze, 1999) (barium has no effect on resting membrane potential or at potentials more negative than the resting potential). However, outward voltage-gated potassium currents are present at potentials depolarized from the resting membrane potential (Fig. 5A). The effect of $\mathrm{CsCl}$ on these various potassium currents was examined. When $5 \mathrm{~mm} \mathrm{CsCl}$ was added to the bath (Fig. 5B), no effect was observed on the kinetics and magnitude of the total outward potassium currents, whereas $I_{\mathrm{H}}$ was completely blocked. The peak outward potassium current at $+30 \mathrm{mV}$ was $4385 \pm 426$ and $4272 \pm 367 \mathrm{pA}$ in the absence and presence of $\mathrm{CsCl}(n=11 ; p>0.05)$, respectively. This result supported the use of $\mathrm{CsCl}$ as a tool to specifically inhibit $I_{\mathrm{H}}$ without effects on outward potassium currents in nodose neurons.

\section{Effect of cAMP on the activation of $I_{\mathrm{H}}$}

HCN1 is reported to be poorly sensitive to cAMP, whereas the $\mathrm{HCN} 2$ and $\mathrm{HCN} 4$ are, in order, increasingly more sensitive (Santoro et al., 1998; Ludwig et al., 1998, 1999; Seifert et al., 1999; Ishii et al., 1999, 2001; for review, see Kaupp and Seifert, 2001). This sensitivity appears as a shift in the activation curve toward more depolarized potentials and an increase in the rate of activation. Because the larger neurons that did not express a C-type neuronal marker were heavily labeled for $\mathrm{HCN1}$, we speculated that the $I_{\mathrm{H}}$ current in A-type neurons would be relatively insensitive to cAMP. We used the absence of TTX-R current and the presence of large $I_{\mathrm{H}}$ currents to identify A-type neurons (Doan and Kunze, 1999), although we realized that a subpopulation of A $\delta$ cells may possess small TTX-R current and were therefore not included in this group. Membrane permeable forms of cAMP [8-Br-cAMP and p-chlorophenylthio (CPT)-cAMP at 0.1-1.0 mM] were applied to six such neurons, and activation curves were obtained from tail current measurements under voltage clamp. In our previous studies, the $I_{\mathrm{H}}$ current in these neurons was large with the major component activating rapidly, with an activation $\tau(73 \pm 3$ msec) in the range of exogenously expressed HCN1 (Doan and Kunze, 1999). Although the immunohistochemical studies indicate that these neurons also contain HCN2 and HCN4, cAMP produced only a very small rightward or no shift in the activation curve of $I_{\mathrm{H}}$ (range, $\left.0-2 \mathrm{mV}\right) . V_{1 / 2}$ for activation curve was $83.0 \pm$ 1.5 and $81.9 \pm 1.4$ in control and cAMP, respectively $(n=6)$ (Fig. $6 A, B)$. We also studied three A-type neurons, in which cAMP $(100 \mu \mathrm{M})$ was added to the pipette, and the response to the voltage protocol $(-80$ to $-110 \mathrm{mV}$ ) was monitored for 4-8 min immediately after entering the cell. There was no effect of the agonist over this time period on tail currents. Finally, we also applied forskolin $(20 \mu \mathrm{M})$ to two A-type neurons again with no effect. In contrast, five of six neurons with TTX-resistant current and smaller $I_{\mathrm{H}}$ currents responded to cAMP with a shift in $V_{1 / 2}$ for the activation curve from $-94 \pm 1.8$ in control to $-86 \pm 1.7 \mathrm{mV}$ $(n=5)$ in the presence of cAMP (Fig. 6C,D). The rate of activation was also increased in the presence of the cyclic nucleotides in four of the five C-type neurons that responded with the shift in activation. At $-120 \mathrm{mV}$, the fast $\tau$ for activation decreased from $213 \pm 29$ to $182 \pm 30 \mathrm{msec}$. One neuron with TTX-resistant current did not respond to PCPT-cAMP, even at $1 \mathrm{mM}$.

\section{Effect of $\mathrm{CsCl}$ during current-clamp recordings}

The soma of the nodose neuron was used as a model to study the effect of $\mathrm{CsCl}$ on membrane excitability and as a predictor of the response at the peripheral terminals. We had shown previously that $\mathrm{CsCl}$ hyperpolarized the neuron demonstrating that $I_{\mathrm{H}}$ is active at the resting membrane potential (Doan and Kunze, 1999). Consistent with this, after superfusion with $\mathrm{CsCl}$, there was a significant hyperpolarization of the resting membrane potential from $-63 \pm 1 \mathrm{mV}(n=28)$ to $-73 \pm 2 \mathrm{mV}(n=28 ; p<$ 0.001 ) when the membrane potential was monitored in currentclamp mode. An example of the response of one neuron to depolarizing current injections in the presence and absence of $\mathrm{CsCl}$ is shown in Figure 7. This figure illustrates a decrease in threshold current needed to evoke discharge (Fig. 7A) and an increase in frequency-number of action potentials at potentials above threshold (Fig. 7B) in the presence of $\mathrm{CsCl}$. The increase in number of action potentials and frequency of occurrence at current steps above threshold in response to $\mathrm{CsCl}$ for eight neurons is summarized in the two graphs in Figure $7 C$. The top panel shows the time of occurrence of action potentials in response to depolarization in four neurons that responded with only one action potential in the absence of $\mathrm{CsCl}$ but multiple action potentials when $\mathrm{CsCl}$ was added to the bathing solution. The four neurons illustrated in the bottom panel responded with two or more action potentials in control and increased the number and frequency of discharge in $\mathrm{CsCl}$. The change in threshold current needed to produce an action potential was also demonstrated in an additional nine neurons in which a current step of $10-100 \mathrm{pA}$ that produced no action potentials in control bath elicited one to two action potentials in the presence of $\mathrm{CsCl}$. The resting mem- 

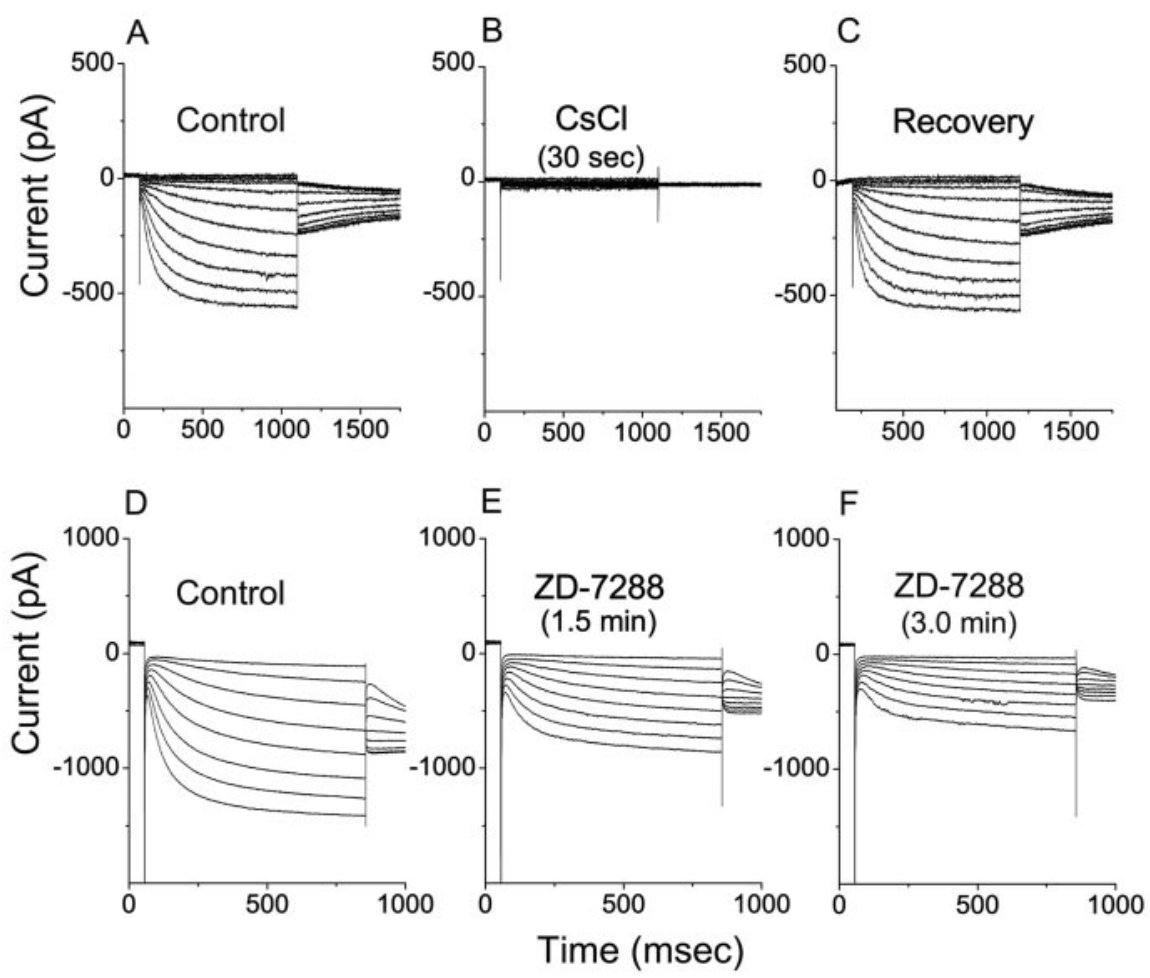

Figure 4. Whole-cell voltage-clamp recordings of $I_{\mathrm{H}}$ in isolated nodose neurons. $A-C$, Representative current traces of $I_{H}$ measured in physiological saline $(A), 30 \mathrm{sec}$ after addition of $5 \mathrm{~mm} \mathrm{CsCl}(B)$, or after washout of $\operatorname{CsCl}(C)(n=15)$. D-F, Representative current traces of $I_{H}$ in a different neuron in the absence $(D)$ and presence $(E, F)$ of $100 \mu \mathrm{m} \mathrm{ZD7288}(n=14)$ for the time indicated. The intracellular pipette contained high potassium-aspartate solution. The neurons were held at $-40 \mathrm{mV}$ and pulsed in $10 \mathrm{mV}$ step increments to potentials between -40 and $-130 \mathrm{mV}$ for $1 \mathrm{sec}(A-C)$ or between -50 and $-120 \mathrm{mV}$ for $850 \mathrm{msec}(D-F)$ followed by a step to $-80 \mathrm{mV}$ before returning to holding potential.
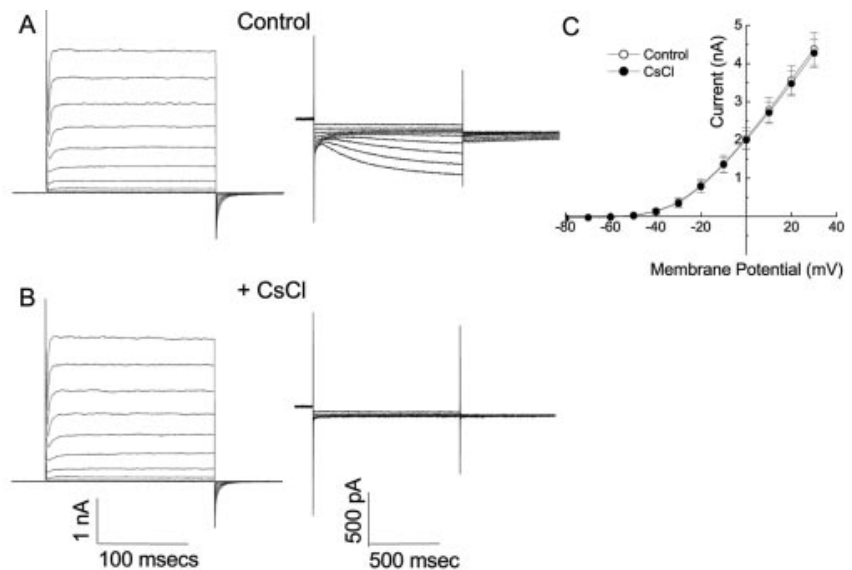

Figure 5. CsCldid not affect outward potassium currents in isolated nodose sensory neurons. $A$, Representative whole-cell voltage-clamped recordings of outward potassium currents (left panel) from a holding potential of $-80 \mathrm{mV}$ and stepped in $10 \mathrm{mV}$ increments to $30 \mathrm{mV}$ for 250 $\mathrm{msec}$. The right panel shows activation of $I_{H}$ in the same neuron in response to hyperpolarizing steps of -70 to $-130 \mathrm{mV}$ from $-40 \mathrm{mV}$ holding potential. $B$, The same protocol in $A$ is applied after addition of $5 \mathrm{~mm} \mathrm{CsCl}$ to the bath solution. Outward potassium currents were unchanged (left panel), whereas $I_{H}$ is blocked (right panel). C, Average outward potassium currents measured at the steady-state component in the absence $(\bigcirc)$ and presence $(O)$ of $\mathrm{CsCl}(n=11)$. In these experiments, sodium and calcium in the extracellular solution were replaced by $\mathrm{N}$-methyl-d-glucamine.

brane potential in the presence of $\mathrm{CsCl}$ for this set of nine neurons was $-65.6 \mathrm{mV}$ as compared with $-61.1 \mathrm{mV}$ in the control.

Input resistance at the resting potential $(-53$ to $-65 \mathrm{mV}$ in this set of neurons) increased from $1.3 \pm 0.45$ to $2.2 \pm 0.69 \mathrm{G} \Omega$ $(n=7)$ when $\mathrm{CsCl}$ was added to the superfusate. This increase in input resistance produced by blocking $I_{\mathrm{H}}$ would be expected to produce more depolarization with the same current injection over the range where $I_{\mathrm{H}}$ was active. In addition, recovery of sodium current from inactivation when the neurons are hyperpolarized by the addition of $\mathrm{CsCl}$ would be expected to contribute to the more robust response (Schild and Kunze, 1997). To eliminate the latter effect, a set of experiments was performed in which membrane potential was returned by current injection to pre- $\mathrm{CsCl}$ levels in the continued presence of $\mathrm{CsCl}$. Under this condition, a current injection that did not elicit an action potential in control solution was still effective in producing discharge (Fig. 8A) and, in cases where repetitive discharge was already present, there was an increase in the number of action potentials in response to the same current injection (Fig. $8 \mathrm{~B}$ ). This suggests that the increase in input resistance produced by blocking $I_{\mathrm{H}}$ contributes to, at least in part, the increase excitability of the nodose neurons.

The CsCl-induced excitability at the soma was also studied during a depolarizing ramp protocol. This protocol was used to simulate the ramp pressure changes used for the in vitro aortic depressor nerve study described below. In physiological saline solution, nodose neurons gradually depolarized during a series of depolarizing current ramp injections (Fig. 9). In the presence of $\mathrm{CsCl}$, there was the expected hyperpolarization of the resting membrane potential. In addition, there was an increase in excitability of the neuron during the depolarizing ramp protocol. In nine cells, the time to first spike for a ramp current of 1.33 $\mathrm{pA} / \mathrm{msec}$ was decreased by $4.0 \pm 1.5 \mathrm{msec}$ in the presence of $\mathrm{CsCl}$.

\section{Presence of $\mathrm{HCN}$ immunoreactivity on the baroreceptor terminals}

We were interested in whether protein expression extended to the sensory receptors. Baroreceptor terminals arising from myelinated fibers lose their myelin sheath and generally have either convoluted "bush" endings or "club" endings in which the fiber terminates abruptly with a slight enlargement (Bock and Gorgas, 1976; Krauhs, 1979). Nonmyelinating Schwann cells often cover the nerve terminals. Unmyelinated fibers terminate as fine endings traveling with, and wrapping around, the myelinated fibers or alternatively forming nerve nets (Krauhs, 1979). In these studies, neuronal markers, anti-PGP 9.5, anti-peripherin, and an anti-neurofilament mixture of NFs 200, 160, and 68 were used to locate the fiber terminals within the adventitia for subsequent colocalization with HCN antibodies. Figure 10 illustrates colocalization of HCN1 with a PGP 9.5-labeled receptor terminal of myelinated fiber identified by its bush morphology. Anti-HCN2 and anti-HCN4 immunoreactivity also appeared with neurofilament immunoreactivity in these bush terminals. However, $\mathrm{HCN} 1$ did not colocalize with fine fibers as seen by the example in Figure 11, which shows a fine unmyelinated fiber traveling with postmyelinated club ending. The latter colocalizes with HCN1, 
whereas the former does not. We saw no fine fibers that expressed HCN1 (>30 unmyelinated fibers examined in four aortic arch preparations). In contrast, $\mathrm{HCN} 4$ and HCN2 appeared in the unmyelinated fibers (Fig. 11). Interestingly, HCN2 and $\mathrm{HCN} 4$, but not HCN1, were also present in non-neuronal cells that surrounded the terminal ending. These cells were labeled by anti-S-100 (data not shown).

\section{Effect of $\mathrm{CsCl}$ on the pressure-discharge relationship of the aortic depressor nerve}

Because $\mathrm{CsCl}$ appears to be a specific inhibitor of $I_{\mathrm{H}}$ for nodose neurons, we investigated its effect on the pressure-discharge relationship of single fibers teased from the aortic depressor nerve innervating the aortic arch. During a ramp increase in pressure, the nerve began to respond at $\sim 90 \mathrm{mmHg}$ (threshold pressure) at a frequency of $\sim 10 \mathrm{~Hz}$ (threshold frequency) (Fig. 12A). As the pressure was increased, the discharge of the nerve increased in a hyperbolic manner. The discharge reached a saturation frequency of $60 \mathrm{~Hz}$ at a saturation pressure of $140 \mathrm{mmHg}$. After perfusion of $\mathrm{CsCl}$ through the aortic arch, the nerve began to discharge at a lower threshold pressure extending the curve to the left. This effect on the pressure threshold was reversed during return to cesium-free bath solution. Data describing the relationship between pressure and discharge for myelinated fibers are summarized in Figure 12D. Cesium (5 mM) decreased the average threshold pressure, increasing the sensitivity of the receptor in the region near threshold $(p<0.05$; see Materials and Methods), but the frequency of discharge at threshold, maximum pressure, and maximum frequency were not significantly different when compared in the presence and absence of cesium chloride (data not shown).

\section{Discussion}

This study made three major contributions. The first is the demonstration that inhibition of $I_{\mathrm{H}}$ in the sensory neurons consistently decreases the current threshold for initiation of activity in response to a depolarizing stimulus, rendering the neurons more excitable. The increase in input resistance resulting from suppression of the $I_{\mathrm{H}}$ current is sufficient to increase the excitability of the neurons over the voltage range where $I_{\mathrm{H}}$ provides a major contribution to the total membrane current, specifically at potentials more negative than approximately $-45 \mathrm{mV}$. This is independent of an additional expected contribution of TTX-sensitive sodium channels to the increased excitability when inactivation is partially removed at the hyperpolarized resting membrane potential (Ikeda et al., examine the tail currents.
A-type Neurons
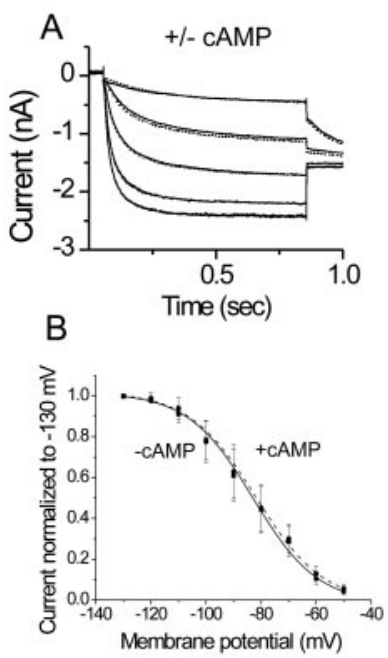

C-type Neurons
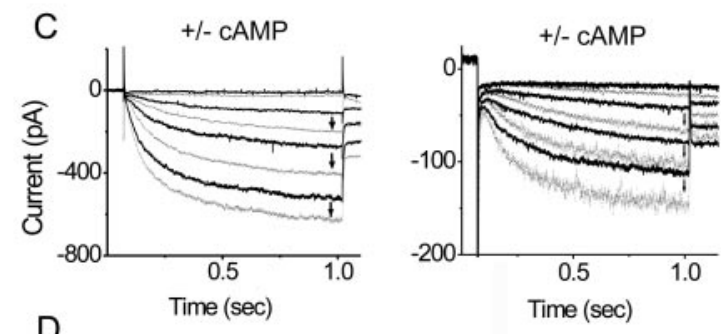

Figure 6. The effect of CAMP analogs on the activation of $\mathrm{A}$ - and C-type neurons. $A$, Example of the current responses to hyperpolarizing voltage steps to $-70,-90,-110,-130$, and $-140 \mathrm{mV}$ from $-40 \mathrm{mV}$ in the presence and absence of pCPT-CAMP $(100 \mu \mathrm{m})$ in an A-type neuron. A-type neurons were distinguished on the basis of the absence of TTX-resistant sodium currents. Tail current measurements were used to obtain activation curves in the presence $(+)$ and absence $(-)$ of cAMP. The normalized activation curves were fitted to a Boltzmann distribution. $B, V_{1 / 2}$ of the activation curve in A-type neurons $(n=6)$ was $83 \pm 1.5$ in control (solid line, open circle) and $81 \pm 1.9$ in 0.1-1.0 mM pCPT-CAMP or 8-Br-CAMP (dashed line, filled circle) with slope values of 12.8 and 13.6, respectively. Three of the six neurons were tested with both 0.1 and $1.0 \mathrm{~mm}$ pCPT-CAMP.C, Examples of two C-type neurons responding to voltage steps from a holding potential of $-40 \mathrm{mV}$ to $-60,-80,-100$, and $-120 \mathrm{mV}$ (left) and $-50,-70,-90$, and $-110 \mathrm{mV}$ (right) in the presence (light traces) and absence (dark traces) of pCPT-CAMP or 8-Br-CAMP $(100 \mu \mathrm{M})$. For the last three voltage steps, the change in current at the same voltage is indicated by arrows. The set of traces on the right were uncorrected for cesium-insensitive current. D, CAMP analogs produced a depolarizing shift in the activation curves of C-type neurons from the control value for $V_{1 / 2}$ of $-94 \pm 1.8 \mathrm{mV}$ (solid line, filled triangles) to $-86 \pm 1.7 \mathrm{mV}$ (dashed line, filled circles); $n=5$ neurons. The membrane potential was held at $-40 \mathrm{mV}$ and $850 \mathrm{msec}$, or $1-2 \mathrm{sec}$ prepulses from -50 to $-120 \mathrm{mV}(B)$ or $-140 \mathrm{mV}(D)$ was applied in $10 \mathrm{mV}$ steps. The membrane potential was returned to $-80 \mathrm{mV}$ to
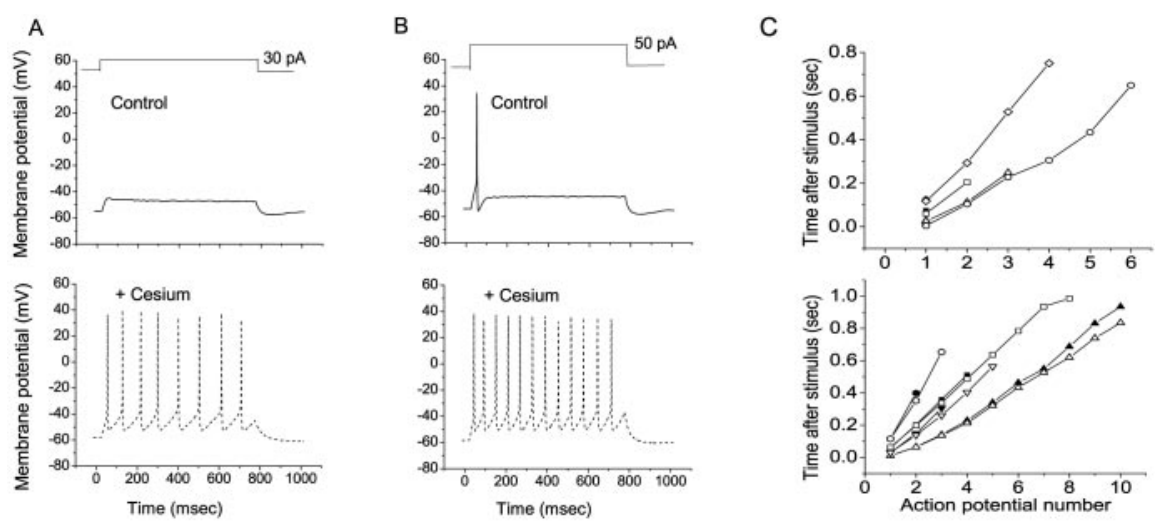

Figure 7. $\quad \mathrm{CsCl}$ hyperpolarizes the resting membrane potential and increases generation of action potentials in response to a depolarizing current step. $A, B$, Representative changes in membrane potential during a 750 msec step depolarizing current injection of $30(A)$ and $50(B)$ pA in the absence (solid line; top panel) and presence (dashed line; bottom panel) of $5 \mathrm{~mm} C \mathrm{Cs}$. C, The top panel summarizes data for four neurons that responded with only one action potential in control (closed symbols) but two or more in the presence of $\mathrm{CsCl}$ (open symbols). Bottom, Four neurons that produced multiple action potentials in control solution (closed symbols) increased their frequency or number of potentials in $\mathrm{CsCl}$ (open symbols). Each symbol represents a different neuron. Similar results were obtained for a total of 15 neurons.

1986; Schild and Kunze, 1997). Maccaferri and colleagues (Maccaferri et al., 1993; Maccaferri and McBain, 1996) have previously reported inhibition of $I_{\mathrm{H}}$ hyperpolarized hippocampal CA1 neurons and, when the membrane potential was returned to preblock levels in the continuous presence of the blocking agent, there was an increase in excitability. Poolos et al. (2002) recently 

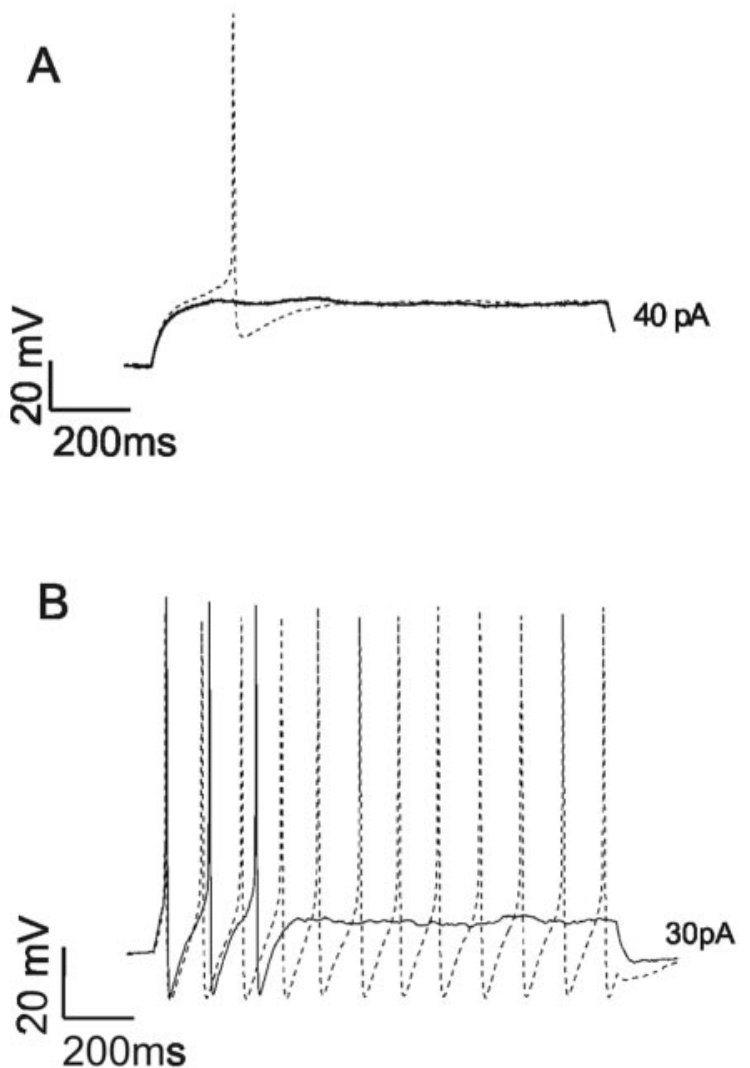

Figure 8. CsCl reduced the threshold for action potential generation from the same initial membrane potential. The membrane potential was returned to pre-CsCl values in the continued presence of CsCl via current injection. Two representative cells illustrating the discharge to increasing current injections in the absence (solid line) and presence (dashed line) of $1 \mathrm{~mm} \mathrm{CsCl}$ are shown. $A$, The neuron that was quiescent in control solution discharged a single action potential in the presence of $\mathrm{CSCl}$ with a $40 \mathrm{pA}$ current injection. $B$, A neuron that produced three spikes in response to a $30 \mathrm{pA}$ current injection in control solution produced repetitive discharge in the presence of $\mathrm{CsCl}$.
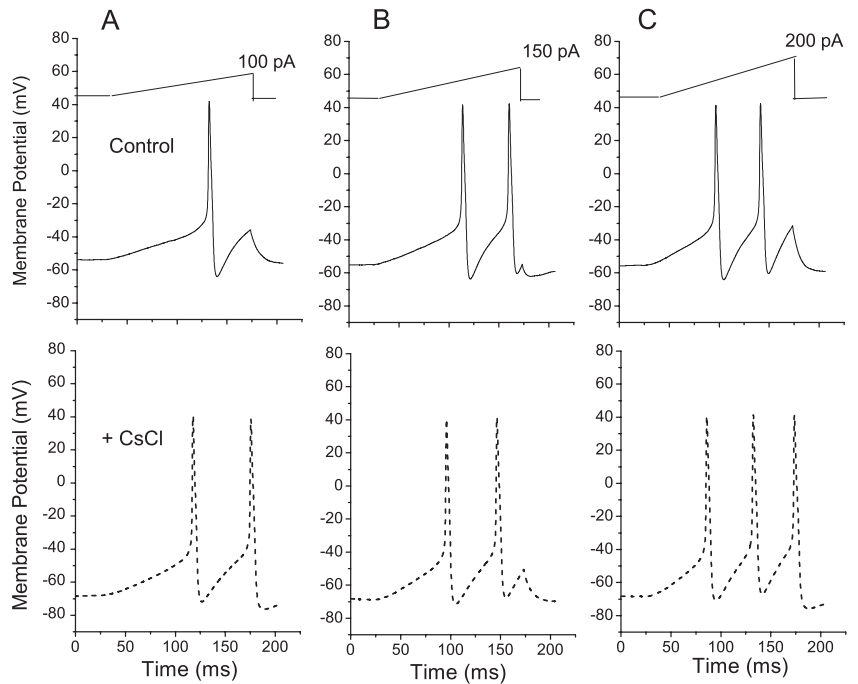

Figure 9. CsCl increased the discharge of nodose neurons during a depolarizing current ramp injection. $A-C$, Representative changes in membrane potential of a nodose neuron during ramp depolarizing current injections at $0.67 \mathrm{pA} / \mathrm{msec}(A), 1.0 \mathrm{pA} / \mathrm{msec}(B)$, and $1.33 \mathrm{pA} / \mathrm{msec}(C)$ in the absence (solid line) and presence (dashed line) of $5 \mathrm{~mm}$ CsCl.
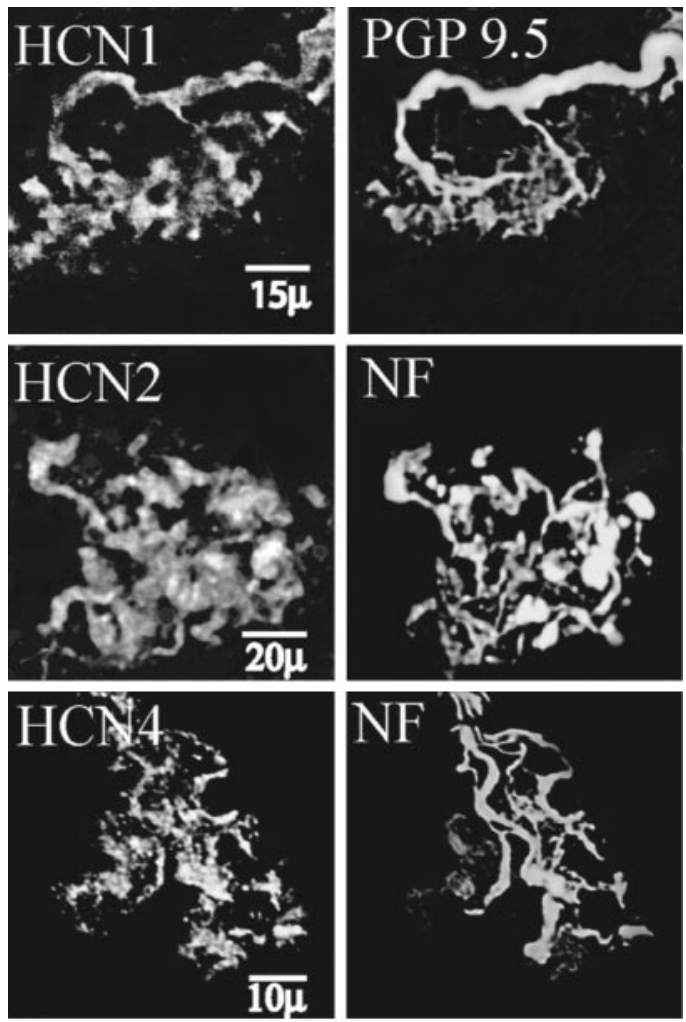

Figure 10. HCN immunoreactivity in aortic baroreceptor terminals of myelinated fibers. Top, A collapsed Z-series stack of $0.4 \mu \mathrm{m}$ confocal sections through a bush baroreceptor terminal shows localization of HCN1 (left) and PGP9.5 (right). PGP9.5 is a ubiquitin hydrolase expressed in neuronal-neuroendocrine cells. Middle, Bush ending is colabeled with HCN2 on the left and the neurofilament mixture on the right. Bottom, HCN4 immunoreactivity on the left is localized to the bush ending identified using the neurofilament mixture (right).
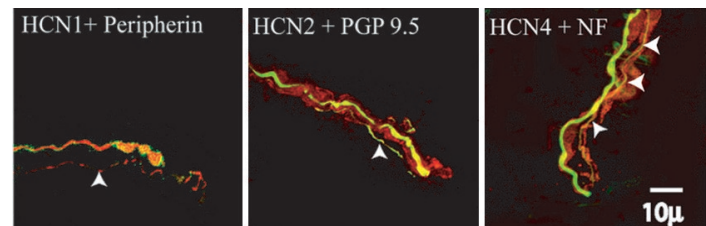

Figure 11. HCN immunoreactivity in club endings of myelinated fibers accompanied by fine unmyelinated fibers. Left, HCN1 (FITC) colocalized (yellow) with peripherin (Rhodamine Red-X) in a club ending but not with fine unmyelinated fiber (arrowhead). Center, HCN2 (Rhodamine Red- $X$ ) appeared in both the fine unmyelinated fibers and in a club ending of a myelinated fiber (yellow). Right, Both club endings and fine fibers (arrowhead) labeled with FITC-NF mixture also expressed HCN4 (Rhodamine Red-X). HCN2 and HCN4 (Rhodamine Red-X) are also found in cells surrounding the fibers.

used a different approach to examine the role of $I_{\mathrm{H}}$ in dendrites of hippocampal pyramidal neurons. They showed that an increase in $I_{\mathrm{H}}$ reduced dendritic excitability, consistent with the present results. $\mathrm{CsCl}$ can also modify the pattern of discharge in repetitively discharging cells. However, the pattern of discharge depends on the other voltage-dependent currents that are activated during the discharge period, and these vary among neurons within the nodose population. Therefore, the effect of $\mathrm{CsCl}$ on the discharge pattern of a particular neuron is difficult to interpret until more is known about the other currents contributing to the discharge. Importantly, in contrast to the role of $I_{\mathrm{H}}$ in oscillatory or pacemaker activity in many other cells (DiFrancesco, 1985; Denyer and Brown, 1990; Pape, 1996; Kaupp and Seifert, 

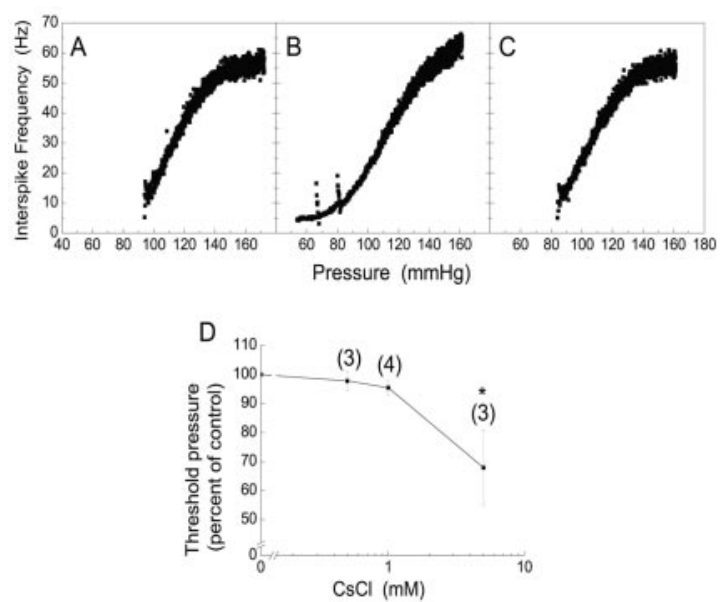

Figure 12. Effect of $\mathrm{CsCl}$ on mechanoreceptor discharge. $A-C$, Pressure-discharge curves of a single representative aortic baroreceptor in response to slow pressure ramp during control $(A)$, perfused with external $\mathrm{CsCl}(B)$, and after washout of $\mathrm{CsCl}(C)$. Points represent instantaneous discharge frequency at a given pressure. The baroreceptor began to discharge at $\sim 90$ $\mathrm{mmHg}$ (threshold pressure) with a frequency of $\sim 10 \mathrm{~Hz}$ (threshold frequency) in control solution. After $15 \mathrm{~min}$ in $5 \mathrm{~mm}$ Cs containing perfusate, threshold pressure dropped to $55 \mathrm{mmHg}$, and the frequency at threshold was $5 \mathrm{~Hz}$. Only 200 data points are plotted in each relationship for clarity. Data analysis was based on the entire set of points ( $>1700$ points for each relationship). $D$, Summary averages for threshold pressure for all aortic baroreceptors tested. Cs (5 mm) decreased the average threshold pressure for discharge. Asterisk indicates significant differences from control $(p<0.05)$. Points are means \pm SEM. Numbers adjacent to data points indicate the number of baroreceptors tested at that concentration.

2001), we found no evidence of a role in oscillatory behavior in the sensory neurons.

The second contribution of this study is the demonstration of differential distribution of $\mathrm{HCN}$ protein in sensory neurons. HCN2 and HCN4 are present in all nodose neurons and the mechanoreceptor terminals of both myelinated and unmyelinated fibers, whereas $\mathrm{HCN} 1$ is expressed in the soma and peripheral terminals of A-type neurons only (see below for overlap in VR1 and HCN1 immunoreactivity). This distribution is consistent with the electrophysiological characteristics of $I_{\mathrm{H}}$ current in A-type neurons versus C-type neurons as reported previously (Doan and Kunze, 1999). In that study, as in the present study, A-type neurons were identified as those that had no TTXresistant sodium current. At $-120 \mathrm{mV}, I_{\mathrm{H}}$ activated with fast time constant of $73 \pm 3 \mathrm{msec}$ in A-type neurons and $163 \pm 37 \mathrm{msec}$ in C-type neurons. Second slower time constants of $682 \pm 83$ and $957 \pm 122 \mathrm{msec}$ were observed in A-type and C-type neurons, respectively. In studies of cloned channels in heterologous expression systems, HCN1 activates with fast $\tau$ values of 24-90 msec within the range found for A-type neurons (Santoro et al., 2000; Altomare et al., 2001; Chen et al., 2001; Ishii et al. 2001; Moosmang et al., 2001; Ulens and Tytgat, 2001). A second slower $\tau$ value of HCN1, in the range of 100 to $400 \mathrm{msec}$, has also been reported (Chen et al., 2001; Ulens and Tytgat, 2001). The amplitude of the fast activating component of $I_{\mathrm{H}}$ in A-type neurons accounts for almost $80 \%$ of the total $I_{\mathrm{H}}$ in these neurons (ratio, 3.7:1) (Doan and Kunze, 1999). Together with the immunohistochemical data that demonstrate strong HCN1 immunoreactivity at the plasma membrane, this suggests that homomeric $\mathrm{HCN} 1$ is the predominate channel responsible for the large $I_{\mathrm{H}}$ in the A-type neurons. Therefore, the lack of effect of cAMP on the $I_{\mathrm{H}}$ in the soma of the A-type neurons may not be surprising. However, $20 \%$ of the current that is more slowly activating in A-type neurons may be, in part, attributable to the cAMP-sensitive subunits
HCN2 and HCN4, rather than the slow component of HCN1. Therefore, one might expect some effect of cAMP on the activation curve in A-type neurons, because coexpression of equal amounts of HCN1 with either HCN2 or HCN4 yields channels with cAMP sensitivity (Chen et al., 2001; Ulens and Tytgat, 2001; Altomare et al., 2003). We do not know yet the subunit arrangements in nodose neurons. Therefore, one possibility for the lack of cAMP effect may be a HCN1:HCN2/4 subunit ratio of 3:1 or an arrangement in a heteromultimer that does not favor cAMP sensitivity. The cAMP sensitivity of such a 3:1 ratio has not been explored. However, Altomare et al. (2003) showed that a concatenated form of $\mathrm{HCN} 1 / \mathrm{HCN} 4$, an HCN4-1 tandem arrangement, had cAMP sensitivity similar to $\mathrm{HCN} 1$ in their expression system. Another possibility for the lack of cAMP effect is that HCN2 and HCN4 are not functionally active in the soma of the neurons expressing HCN1. Experiments such as elimination of $\mathrm{HCN} 1$ with antisense strategies may provide information on this question.

The observation that no HCN1 labeling was seen in the peripheral receptor terminals arising from unmyelinated fibers suggests that the soma that colabeled with $\mathrm{HCN} 1$ and VR1 may also be A-type neurons. In support of this, there are recent reports of capsaicin sensitivity and VR1 labeling in the smaller diameter myelinated fibers of sensory neurons using conduction velocity measurements and electron microscopy, respectively (Carlton and Coggeshall, 2001; Ringkamp et al., 2001). These are also the cells that weakly express HCN1 in contrast to those that show very strong labeling. Finally, whether the mRNA for $\mathrm{HCN} 3$ that is present in nodose ganglia is localized to the neurons or to other cells in the ganglia remains an open question. Relatively little is presently known about the properties of $\mathrm{HCN} 3$ as compared with the other family members (Moosmang et al., 2001).

The third contribution of this study is the first demonstration of a role for $I_{\mathrm{H}}$ at the sensory terminal and is based on the presence of HCN immunoreactivity at the terminals, and the observation that the threshold for aortic arch baroreceptor discharge is lowered by the application of $\mathrm{CsCl}$ to the terminal region. The mechanically initiated depolarization presumably produced by stretch-activated cation current in the nerve terminals (Matsuura, 1973) provides a stimulus that may be mimicked by the depolarizing current delivered to the soma during current-clamp measurements in these studies. If $I_{\mathrm{H}}$ is reduced or blocked, a smaller stimulus would produce a larger depolarization in the face of the increased input resistance. Furthermore, the sodium channels at the terminal region are more available from the hyperpolarized potential. The results presented here on the discharge characteristics of baroreceptors terminals and immunohistochemical localization of HCN channels to the terminals provide support for a functional role for $I_{\mathrm{H}}$ in the peripheral afferent terminal. However, effects of cesium underlying smooth muscle and endothelial cells must also be considered. Changes in smooth muscle tone generally produce a shift in the discharge response curve along the pressure axis that was not observed in these studies (Andresen and Yang, 1992.) Nevertheless, unidentified cesium-sensitive channels at the terminal region remain potential targets that may also modulate discharge.

$I_{\mathrm{H}}$ contributes to setting the membrane potential at the soma (Doan and Kunze, 1999) and presumably at the peripheral terminal. Because this current, particularly in C-type neurons that express only HCN2 and HCN4, can be modulated by cAMP, one would expect that discharge of unmyelinated terminals would be more susceptible to actions of neurotransmitters and modulators that regulate cAMP production. In fact, several studies have shown that C-type neurons, but not A-type neurons, respond to 
agents such as 5-HT, bradykinin, histamine, and acetylcholine that may be linked to cAMP production via G-protein-gated receptors (Higashi and Nishi, 1982; Higashi et al., 1982; Stansfeld and Wallis, 1985). The identity and distribution of these receptors to the sensory terminals and their relationship to $I_{\mathrm{H}}$ are important areas for additional exploration.

\section{References}

Altomare C, Bucchi A, Camatini E, Baruscotti M, Viscomi C, Moroni A, DiFrancesco D (2001) Integrated allosteric model of voltage gating of HCN channels. J Gen Physiol 117:519-532.

Altomare C, Terragni B, Brioschi C, Milanesi R, Pagliuca C, Viscomi C, Moroni A, Baruscotti M, DiFrancesco D, Heteromeric (2003) HCN1HCN4 channels: a comparison with native pacemaker channels from the rabbit sinoatrial node. J Physiol (Lond) 549:347-359.

Andresen MC, Yang MY (1990) Dynamic and static conditioning pressures evoke equivalent rapid resetting in rat aortic baroreceptors. Circ Res 67:303-311.

Andresen MC, Yang M (1992) Smooth muscle tone and rapid resetting of rat aortic baroreceptors. Circ Res 70:116-122.

Arcangeli A, Bianchi L, Becchetti A, Faravelli L, Coronnello M, Mini E, Olivotto M, Wanke E (1995) A novel inward-rectiffying K+ current with a cell-cycle dependence governs the resting potential of mammalian neuroblastoma cells. J Physiol (Lond) 489:455-471.

Block BM, Jones SW (1996) Ion permeation and block of M-type and delayed rectifier potassium channels. Whole-cell recordings from bullfrog sympathetic neurons. J Gen Physiol 107:473-488.

Bock P, Gorgas K (1976) Fine structure of baroreceptor terminals in the carotid sinus of guinea pigs and mice. Cell Tiss Res 170:95-112.

Carlton SM, Coggeshall RE (2001) Peripheral capsaicin receptors increase in the inflamed rat hindpaw: a possible mechanism for peripheral sensitization. Neurosci Lett 310:53-56.

Chen S, Wang J, Siegelbaum SA (2001) Properties of hyperpolarizationactivated pacemaker current defined by coassembly of HCN1 and HCN2 subunits and basal modulation by cyclic nucleotide. J Gen Physiol 117:491-504.

Denyer JC, Brown HF (1990) Pacemaking in rabbit isolated sino-atrial node cells during Cs + block of the hyperpolarization-activated current If. J Physiol (Lond) 429:401-409.

DiFrancesco D (1985) The cardiac hyperpolarization-activated current, $\mathrm{I}_{\mathrm{f}}$. Origins and developments. Prog Biophys Mol Biol 46:163-183.

Doan TN, Kunze DL (1999) Contribution of the hyperpolarizationactivated current $(\mathrm{IH})$ to the resting membrane potential of neonatal rat nodose sensory neurons. J Physiol (Lond) 514:125-138.

Glazebrook PA, Ramierez A, Schild JH, Shieh C-C, Doan T, Wible BA, Kunze DL (2002) Potassium channels, Kv1.1, Kv1.2 and Kv1.6 influence excitability of rat visceral sensory neurons. J Physiol (Lond) 541:467-482.

Harris NC, Constanti A (1995) Mechanism of block by ZD7288 of the hyperpolarization-activated inward rectifying current in guinea pig substantia nigra neurons in vitro. J Neurophys 74:2366-2378.

Higashi H, Nishi S (1982) 5-Hydroxytrytamine receptors of visceral primary afferent neurons on rabbit nodose ganglia. J Physiol (Lond) 323:543-567.

Higashi H, Ueda N, Nishi S, Gallagher JP, Shinnick-Gallagher P (1982) Chemoreceptors for serotonin (5-HT), actylcholine (ACh), bradykinin (BK), histamine $(\mathrm{H})$ and gamma-aminobutyric acid $(\mathrm{GABA})$ on rabbit visceral afferent neurons. Br Res Bull 8:23-32.

Ikeda SR, Schofield GG, Weight FF (1986) $\mathrm{Na}+$ and Ca2+ currents of acutely isolated adult rat nodose ganglion cells. J Neurophysiol 55:527-539.

Ishii TM, Takano M, Xie LH, Noma A, Ohmori H (1999) Molecular characterization of the hyperpolarization-activated cation channel in rabbit heart sinoatrial node. J Biol Chem 274:12835-12839.

Ishii TM, Takano M, Ohmori H (2001) Determinants of activation kinetics in mammalian hyperpolarization-activated cation channels. J Physiol (Lond) 537:93-100

Kaupp UB, Seifert R (2001) Molecular diversity of pacemaker ion channels. Annu Rev Physiol 63:235-257.

Kitchener PD, Wilson P, Snow PJ (1993) Selective labelling of primary sensory afferent terminals in lamina II of the dorsal horn by injection of
Bandeiraea simplicifolia isolectin B4 into peripheral nerves. Neuroscience 54:545-551.

Krauhs JM (1979) Structure of rat aortic baroreceptors and their relationship to connective tissue. J Neurocytol 8:401-414.

Kubo Y, Baldwin TJ, Jan YN, Jan LY (1993) Primary structure and functional expression of a mouse inward rectifier potassium channel. Nature 362:127-133.

Kunze DL, Krauhs JM, Orlea CJ (1984) Direct action of norepinephrine on aortic baroreceptors of rat adventitia. Am J Physiol 247:H811-H816.

Ludwig A, Zong X, Jeglitsch M, Hofmann F, Biel M (1998) A family of hyperpolarization-activated mammalian cation channels. Nature 393:587-591.

Ludwig A, Zong X, Stieber S, Hullin R, Hofmann F, Biel M (1999) Two pacemaker channels from human heart with profoundly different activation kinetics. EMBO J 18:2323-2329.

Maccaferri G, McBain CJ (1996) The hyperpolarization-activated current (Ih) and its contribution to pacemaker activity in rat CA1 hippocampal stratum oriens-alveus interneurones. J Physiol (Lond) 497:119-130.

Maccaferri G, Mangoni M, Lazzari A, DiFrancesco DJ (1993) Properties of the hyperpolarization-activated current in rat hippocampal CA1 pyramidal cells. Neurophysiology 69:2129-2136.

Matsuura S (1973) Depolarization of sensory nerve endings and impulse initiation in common carotid baroreceptors. J Physiol (Lond) 235:31-56.

Mayer ML, Westbrook GL (1983) A voltage-clamp analysis of inward (anomalous) rectification in mouse spinal sensory ganglion neurons. J Physiol (Lond) 340:19-45.

Moosmang S, Stieberm J, Zong X, Bielm M, Hofmannm F, Ludwig A (2001) Cellular expression and functional characterization of four hyperpolarization-activated pacemaker channels in cardiac and neuronal tissues. Eur J Biochem 268:1646-1652.

Moroni A, Barbuti A, Altomare C, Viscomi C, Morgan J, Baruscotti M, DiFrancesco D (2000) Kinetic and ionic properties of the human HCN2 pacemaker channel. Pflügers Arch 439:618-626.

Pape HC (1996) Queer current and pacemaker: the hyperpolarizationactivated cation current in neurons. Annu Rev Physiol 58:299-327.

Poolos NP, Migliore M, Johnston D (2002) Pharmacological upregulation of h-channels reduces the excitability of pyramidal neuron dendrites. Nat Neurosci 5:767-774.

Ringkamp M, Peng YB, Wu G, Hartke TV, Campbell JN, Meyer RA (2001) Capsaicin responses in heat-sensitive and heat-insensitive A-fiber nociceptors. J Neurosci 21:4460-4468.

Santoro B, Liu DT, Yao H, Bartsch D, Kandel ER, Siegelbaum SA, Tibbs GR (1998) Identification of a gene encoding a hyperpolarization-activated pacemaker channel of brain. Cell 93:717-729.

Santoro B, Chen S, Luthi A, Pavlidis P, Shumyatsky GP, Tibbs GR, Siegelbaum SA (2000) Molecular and functional heterogeneity of hyperpolarization-activated pacemaker channels in the mouse CNS. J Neurosci 20:5264-5275.

Schild JH, Kunze DL (1997) Experimental and modeling study of Na current heterogeneity in rat nodose neurons and its impact on neuronal discharge. J Neurophys 78:3198-3209.

Seifert R, Scholten A, Gauss R, Mincheva A, Lichter P, Kaupp UB (1999) Molecular characterization of a slowly gating human hyperpolarizationactivated channel predominantly expressed in thalamus, heart, and testis. Proc Natl Acad Sci USA 96:9391-9396.

Shin KS, Rothberg BS, Yellen G (2001) Blocker state dependence and trapping in hyperpolarization-activated cation channels: evidence for an intracellular activation gate. J Gen Physiol 117:91-101.

Stansfeld CE, Wallis DI (1985) Properties of visceral primary afferent neurons in the nodose ganglion of the rabbit. J Neurophys 54:245-260.

Ulens C, Tytgat J (2001) Functional heteromerization of HCN1 and HCN2 pacemaker channels. J Biol Chem 276:6069-6072.

Vaccari T, Moroni A, Rocchi M, Gorza L, Bianchi ME, Beltrame M, DiFrancesco D (1999) The human gene coding for HCN2, a pacemaker channel of the heart. Biochim Biophys Acta 1446:419-425.

Wang H, Rivero-Melian C, Robertson B, Grant G (1994) Transganglionic transport and binding of the isolectin B4 from Griffonia simplicifolia I in rat primary sensory neurons. Neuroscience 62:539-551.

Wischmeyer E, Lentes K, Karschin A (1995) Physiological and molecular characterization of an IRK-type inward rectifier $\mathrm{K}+$ channel in a tumor mast cell line. Pflügers Arch 429:809-819. 